\title{
Advérbios monossilábicos pós-verbais no PB: sobre a relação entre sintaxe e prosódia $^{1}$
}

\author{
Post-Verbal Monosyllabic Adverbs in Brazilian \\ Portuguese: On the Relation between Syntax \\ and Prosody
}

Sergio Menuzzi
UNICAMP
Carlos Mioto
UFSC

Abstract

This article discusses the analysis proposed by Costa (1998) for the syntax of monosyllabic adverbs in European Portuguese (EP). Theoretically, the aim is to evaluate the analysis' underlying assumptions about the syntax-prosody interface. Under Costa's proposal, the order [Verb Complement Adverb] involves scrambling of the Complement to the left of the Adverb in EP. His main argument is based on an interaction of the phonological properties of monosyllabic adverbs with Cinque (1993)'s theory of the phrasal stress. Crucially, this theory assumes a very strong relation between syntactic constituents and the prosodic representation relevant for stress assignment. We will argue, however, that the distribution of monosyllabic adverbs, at least in BP, is best explained by autonomous rules of phonological phrase formation, as in Nespor \& Vogel (1986)'s framework. Under this view, the relation between syntactic and prosodic constituents is indirect, and leads us to conclude that the distribution of monosyllabic adverbs does not support Complement scrambling in BP. 


\section{Keywords}

Syntax-phonology interface, Phonological phrases, Nuclear stress, Monosyllabic adverbs, Order of adverbs, Phrase structure of the Portuguese clause.

\section{Resumo}

This article discusses the analysis proposed by Costa (1998) for the syntax of monosyllabic adverbs in European Portuguese (EP). Theoretically, the aim is to evaluate the analysis' underlying assumptions about the syntax-prosody interface. Under Costa's proposal, the order [Verb Complement Adverb] involves scrambling of the complement to the left of the adverb in EP. One of his main arguments is based on an interaction of the phonological properties of monosyllabic adverbs with Cinque (1993)'s theory of the phrasal stress. Crucially, this theory assumes a strong correspondence between syntactic constituents and the prosodic representation relevant for stress assignment. We will argue, however, that the distribution of monosyllabic adverbs, at least in Brazilian Portuguese [BP], is best explained by more autonomous rules of phonological phrase formation, as in Nespor \& Vogel (1986)'s framework. Under this view, the relation between syntactic and prosodic constituents is indirect, and the distribution of monosyllabic adverbs does not provide any support for complement scrambling in BP.

\section{Palavras-chave}

Interface sintaxe-fonologia, Sintagmas fonológicos, Acento nuclear, Advérbios monossilábicos, Ordem dos advérbios, Estrutura sintagmática da frase portuguesa 


\section{INTRODUÇÃO}

$\mathrm{H}$

á um fato básico que caracteriza a correlação entre foco e ordem dos constituintes pós-verbais: quando o foco é um complemento ou um adjunto do verbo, tende a ocupar a posição final da frase, na qual recebe o acento mais proeminente dela - o "acento nuclear" da frase. $\mathrm{O}$ paradigma é bem conhecido e é ilustrado pelos exemplos em (1), adaptados de João Costa (1998, p. 161) (maiúsculas indicam o acento principal, ou "nuclear”, da frase; '\#’ indica frase imprópria para o contexto; de resto, usamse as convenções normais para julgamentos):

(1) A: Que língua o Paulo fala bem?

B: a) Ele fala bem FRANCÊS.

b) \# Ele fala francês BEM.

c) ? Ele fala FRANCÊS bem.

(2) A: O Paulo é um fracasso no inglês. B: E no francês, como ele é?

A: a) (Que eu saiba,) ele fala francês RAZOAVELMENTE.

b) \# (Que eu saiba), ele fala razoavelmente FRANCÊS.

c) ? (Que eu saiba), ele fala RAZOAVELMENTE francês.

Note-se, entretanto, que complementos ou advérbios podem ser focalizados mesmo quando não estão em posição final, sem que o resultado seja “terrível", fato que colocaremos de lado aqui. Na discussão que segue, vamos nos concentrar nas generalizações básicas ilustradas por (1a) e (2a) e esquematizadas em (3):
a. Foco no adjunto:
[ $\mathrm{V}$ Compl ADV ]
b. Foco no complemento:
[ $\mathrm{V}$ Adv COMPL ] 
As questões mais gerais por trás de (3) que interessam aqui são: (a) qual a sintaxe dessas ordens? (b) como ela se relaciona com a atribuição de acento nuclear ao constituinte em posição final? Portanto, não discutiremos os aspectos interpretativos, informacionais, da expressão de foco em português; antes, vamos nos concentrar num aspecto particular da relação entre sintaxe e prosódia em português: especificamente, discutiremos um argumento de João Costa (1998), baseado no que chama de "advérbios monossilábicos", em favor de uma análise sintática específica das ordens em (3).

A questão que guiará nossa discussão é basicamente uma: o comportamento de tais advérbios justifica uma relação mais íntima entre sintaxe e prosódia, como a assumida por João Costa, seguindo Cinque (1993), ou indica, ao contrário, um grau maior de autonomia da organização prosódica? A última alternativa, é claro, tem conseqüências para a análise sintática proposta, pois indica que o comportamento "sintático" prosodicamente condicionado pode não ser um bom diagnóstico para a identificação das estruturas sintagmáticas correspondentes.

Antes de iniciar a discussão, fazemos uma ressalva: o presente trabalho toma como ponto de partida a descrição que João Costa (1998) faz da relação entre foco, acento nuclear e ordem de palavras à direita do verbo no português europeu (PE); mas trata-se de um trabalho sobre nossos julgamentos, portanto, sobre o português brasileiro (PB). A descrição e a análise de João Costa nos parecem bons pontos de partida porque o PB e o PE se comportam de modo semelhante em relação a paradigmas como (1) e (2). Entretanto, a discussão de João Costa envolve também estruturas de inversão do sujeito que não possuem correspondentes em PB (ver, especialmente, seu capítulo 3), o que poderia indicar que o PB e o PE não são gramáticas completamente correspondentes no que trata das ordens em (3). Portanto, é possível que as observações descritivas que fazemos aqui não se estendam ao PE, e, do mesmo modo, que as conclusões teóricas a que chegamos baseadas nelas também não se apliquem quando se consideram os fatos daquela língua. 


\section{DUAS ANÁLISES}

João Costa (1998; ver também COSTA, 2003) propõe, para a sintaxe da ordem dos constituintes pós-verbais em PE, uma análise semelhante à proposta por Neeleman \& Reinhart (1998) para o holandês. Essas análises são, por sua vez, baseadas na teoria de Cinque (1993) para a relação entre sintaxe e a atribuição do acento nuclear, segundo a qual recebe o acento nuclear o constituinte que estiver "mais encaixado" na estrutura sintagmática da frase (ver também REINHART, 2003). Assim, segundo João Costa, no caso da ordem [V Adv COMPL], temos em PE a seguinte estrutura sintagmática:

(4)

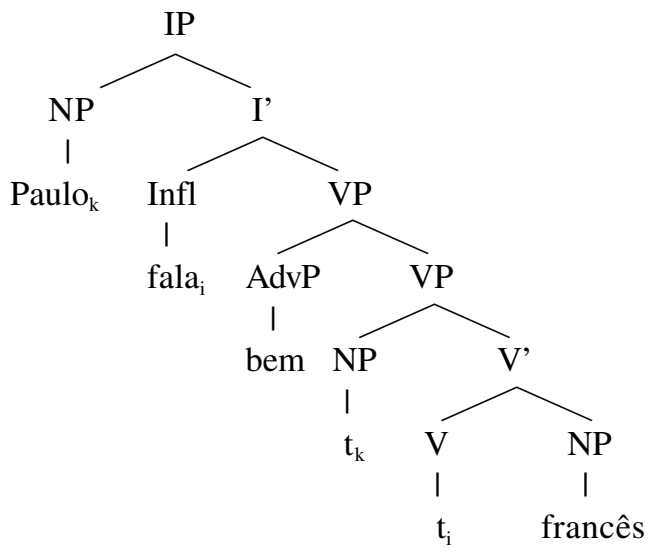

Em (4), todos os constituintes, exceto o $\mathrm{V}$ e o NP sujeito, estão em sua posição de base. O complemento é o constituinte "mais encaixado" da estrutura e recebe, portanto, o acento nuclear do modo previsto pela teoria de Cinque. Observe-se ainda que, nesta análise, os adjuntos penderiam à esquerda do VP.

Seguindo a teoria de Cinque, é preciso que, na ordem [V Compl ADV], o adjunto se torne o constituinte "mais encaixado" da frase. A análise tradicional, segundo a qual essa ordem resulta do fato de o adjunto pender à direita do VP "na base", como em (5), não é compatível com esse modo de conceber a relação entre sintaxe e a atribuição de acento nuclear: 
(5)

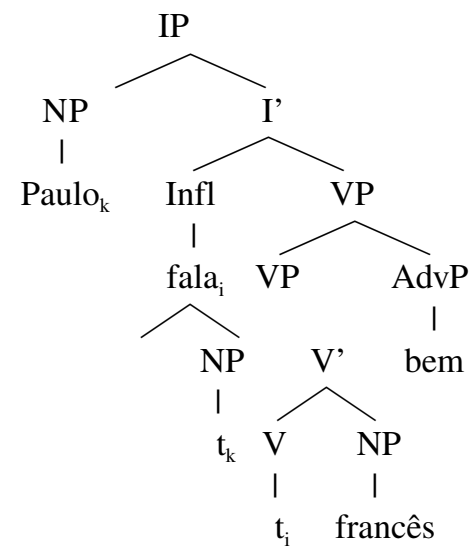

Por essa e por outras razões, na análise de João Costa, a ordem [V Compl ADV] é derivada por scrambling, isto é, por movimento à esquerda do complemento e sua adjunção ao VP (essencialmente do mesmo modo em que a ordem [Compl ADV V] é derivada em uma língua OV como o holandês), como vemos em (6):

(6)

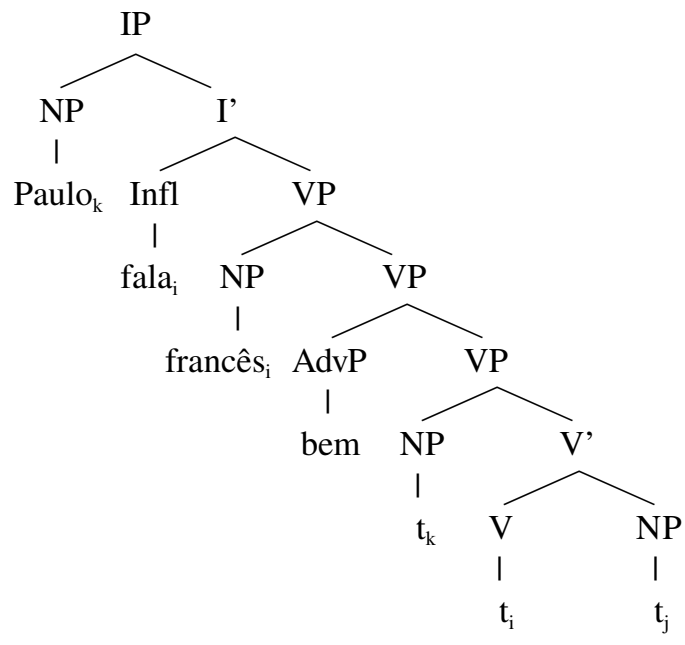

Em (6), o adjunto é o constituinte "mais encaixado" da estrutura sintagmática da frase; assim, de acordo com a teoria de Cinque, ele pode receber o acento nuclear, como desejado. Note-se que, em (6), novamente o adjunto pende à esquerda do VP, embora nesse caso, em princípio, pudéssemos 
conservar essencialmente a mesma análise se o adjunto pendesse à direita do VP: a ordem de superfície seria a mesma e o adjunto continuaria sendo o constituinte mais encaixado da frase. Nesse caso, portanto, o argumento a favor da posição do adjunto, e da adjunção à esquerda, é de simplicidade, mas não empírico. Mais adiante, veremos que João Costa apresenta um argumento empírico a favor da adjunção de bem à esquerda do VP.

Neste ponto, importa enfatizar aquele aspecto da teoria do acento nuclear de Cinque que motiva, ao menos parcialmente, a análise de João Costa: como a atribuição do acento nuclear é diretamente dependente da estrutura sintagmática da frase, ela exige que essa estrutura seja arranjada de modo que o acento sempre corresponda ao constituinte mais encaixado. Por isso, o movimento de scrambling dos complementos é "prosodicamente motivado": é ele que faz com que o complemento deixe de ser o constituinte mais encaixado, e o adjunto fique na posição adequada para receber o acento nuclear - podendo tornar-se, então, o foco não marcado da frase). Como SamekLodovici (2005) apontou, se, por um lado, esse tipo de abordagem enfatiza a relação entre sintaxe e acento nuclear (ZUBIZARRETA, 1998, segue linha similar), de outro acaba divorciando o tratamento dado ao acento nuclear do tratamento dado aos demais processos de estruturação prosódica da frase, como por exemplo o da construção dos sintagmas fonológicos e a localização dos demais acentos (secundários) da frase (ver, por exemplo, a discussão de (39) e (40).

É claro que esse modo de conceber a relação entre sintaxe e prosódia - em particular, a relação entre sintaxe e acento nuclear - não é necessário. Em primeiro lugar, ele não é o sustentado pela maioria dos fonólogos desde que Nespor \&Vogel (1986) ("N\&V”, daqui por diante) argumentaram que a estrutura sintática determina a organização prosódica da frase apenas indiretamente. E há mesmo alternativas sintáticas para a relação entre os elementos à direita do verbo e o acento nuclear, como na extensão da abordagem cartográfica proposta recentemente por Belletti (2004).

$\mathrm{Na}$ análise de Belletti, o constituinte a ser focalizado deve ser movido para o Spec de um "Focus Phrase" localizado na periferia esquerda do VP. A interface sintaxe-prosódia não se dá, portanto, por uma correspondência entre configurações específicas aos dois componentes (entre encaixamento sintático e proeminência métrica). Antes, uma operação sintática geral - a checagem de traços - deve fornecer uma instrução para o componente prosódico 
(“atribua acento nuclear ao constituinte em Spec de FocP"). De um ponto de vista minimalista, há talvez uma vantagem nesta análise: o constituinte movido é sempre o focalizado, e o movimento se dá para a checagem de seus traços, obedecendo a Greed. Isso não se aplica ao scrambling proposto por João Costa, em que um constituinte é movido para que outro possa receber o acento nuclear (e ser focalizado). (Ver, entretanto, REINHART, 2003, para uma discussão detalhada desta última derivação dentro de um quadro minimalista.)

Para nossos objetivos aqui, a alternativa sugerida por Belletti oferece pouco interesse imediato, já que não desenvolve uma análise detalhada da relação entre sintaxe e prosódia. Retornemos, então, à concepção geral corrente em fonologia, na qual a estrutura prosódica possui uma autonomia relativa com relação à sintaxe. Em particular, muitos fonologistas sustentam que não há correspondência direta entre sintagmas sintáticos e sintagmas fonológicos, e que a atribuição de acentos à frase não depende dos primeiros, e sim dos últimos. Para exemplificar essa abordagem, considere a seguinte análise informal da acentuação frasal do português, em que adaptamos a teoria do acento de Halle \& Vergnaud (1987) à teoria da hierarquia prosódica de $\mathrm{N} \& \mathrm{~V}:^{2}$

(7) a. Construa um sintagma fonológico agrupando em um constituinte prosódico $\phi$ : (i) um núcleo lexical $\mathrm{X}$ (= V, N, Adj ou Adv) e (ii) todo modificador de $\mathrm{X}$ à sua esquerda, até a fronteira de um outro sintagma fonológico $\phi$ '.

b. Interprete as fronteiras de um sintagma fonológico como um constituinte métrico ilimitado (ing. unbounded) com núcleo-à-direita (ing. right-headed).

c. Interprete as fronteiras de um grupo entoacional como um constituinte métrico ilimitado com núcleo-à-direita.

A regra em (7a) segmenta a frase em sintagmas fonológicos, seguindo em linhas gerais a análise de $\mathrm{N} \& \mathrm{~V}$ para os sintagmas fonológicos do italiano (cf. (5), p.168, de N\&V); a regra em (7b) atribui a cada sintagma fonológico $\phi$ um acento frasal (tornando a última sílaba acentuada de $\phi$ à direita sua sílaba mais proeminente); e a regra em (7c) atribui o "acento nuclear" à frase (tornando a sílaba mais proeminente de seu último $\phi$ a sílaba mais proeminente da frase). O que é crucial, nesse ponto, para nós é que, por (7a), um sintagma fonológico não corresponde diretamente a um sintagma sintático em português: 
um sintagma fonológico não conterá, em regra, o material à direita de um núcleo, salvo em casos de "reanálise", que mencionaremos a seguir. ${ }^{3}$

Em (8) ilustramos a operação de (7): de acordo com (7a), a frase em (8a) recebe a análise em sintagmas fonológicos em (8b); e as regras de atribuição de acento em $(7 b, c)$, constroem a grade métrica em (8c) (acentos secundários, sinalizados por '.' nas linhas 4 e 5 da grade, são acentos lexicais e frasais não promovidos a acento nuclear da frase):

a. Paulo já conhecia uma das irmãs de Maria.

b. $(\text { Paulo })_{\phi}(\text { já conhecia })_{\phi}(\text { uma das irmãs })_{\phi}(\text { de Maria })_{\phi}$

\begin{tabular}{|c|c|c|c|c|}
\hline$($. & & & $*)$ & grupo entoacional \\
\hline$)($. & $*)($ & *) ( & $*)$ & sintagma fonológico \\
\hline .) $(*)($. & * $)(*).($. & $*)($. & $\left.*^{*}\right)$ & palavra fonológica \\
\hline
\end{tabular}

c. Paulo já conhecia uma das irmãs de Maria.

No caso específico do tipo de frase que estamos discutindo neste trabalho, como (2a) por exemplo, a análise de $\mathrm{N} \& \mathrm{~V}$ teria como objetivo atribuir a seguinte estrutura prosódica (embora francês deva aparecer como um sintagma fonológico independente por (7a), a análise também permite integrálo ao sintagma prosódico do verbo fala, como em (9), por meio do processo de "reanálise", o qual será objeto de nossa discussão mais adiante):

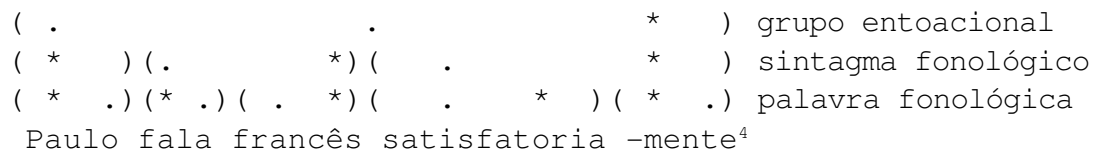

O ponto fundamental aqui é que a construção da representação prosódica pertinente - por meio da qual é atribuído o acento nuclear e, portanto, é identificado o foco não-marcado - é, no essencial, independente da derivação sintática da frase: numa análise com a de $\mathrm{N} \& \mathrm{~V}$, a representação em (9) pode ser obtida seja com uma derivação "tradicional", como (5), seja com a derivação proposta por João Costa em (6), com scrambling do objeto.

Assim, numa teoria em que o acento nuclear da frase é determinado por sua estrutura prosódica e em que esta estrutura é apenas indiretamente determinada pela estrutura sintagmática, não se pode tomar a localização do acento nuclear como um critério para determinação da estrutura sintagmática. 
Em outras palavras, admitida a tese de que há alguma autonomia da estrutura prosódica com relação à estrutura sintagmática, não há razão para que o acento nuclear sobre adjuntos focalizados na ordem [V Compl ADJUNTO] exija uma representação com scrambling do objeto, como em (6). Poder-se-ia muito bem continuar com a análise tradicional, com a adjunção do advérbio à direita do VP, como em (5). A questão, então, é: há outros argumentos a favor de scrambling e contra a adjunção à direita?

\section{CONTRA A ADJUNÇÃO À DIREITA DE ADVÉRBIOS MONOSSILÁBICOS}

Uma das linhas de argumentação de João Costa é mostrar que a ordem [V Compl ADJUNTO] em português apresenta propriedades semelhantes às das estruturas de scrambling em holandês e alemão. Especificamente, são três as propriedades relevantes destas estruturas: (a) só são possíveis com NPs e PPs, mas não com APs predicativos; (b) envolvem movimento-A' do complemento (portanto, adjunção ao VP), já que licenciam lacunas parasitas; e (c) o movimento só se aplica no caso de o complemento ser "específico", ou de não ser informação nova - justamente porque, segundo Neeleman \& Reinhart (1998), o que motiva scrambling é a focalização do adjunto, que requer a "defocalização" do complemento.

Para nossos fins, a propriedade (c) não pode ser tomada como um argumento, pois é precisamente ela que está sub judice: como vimos, é possível conceber a interface entre sintaxe e prosódia de tal modo que o adjunto receba "acento nuclear" na ordem [V Compl ADJUNTO] sem que, para isso, ele precise ser o constituinte "mais encaixado" da frase. O que o faz ser o foco é o acento nuclear e, portanto, é a ausência de acento nuclear que sinaliza a "defocalização" do complemento - seja lá como funciona a atribuição do acento nuclear.

Assim, permanecem as propriedades em (a) e (b), anteriormente indicadas, da argumentação por analogia com scrambling em holandês e alemão. Entretanto, parece-nos que os contrastes que levam a dizer que o PE possui scrambling não se reproduzem em $\mathrm{PB}$, nem no que diz respeito a predicativos (10)-(11), nem a lacunas parasitas (12) (para o PE, ver COSTA, 1998, p.162-3): 
(10) a. O Paulo acha sempre a Maria simpática. (OK em PE, OK em PB)

b. O Paulo acha a Maria simpática sempre. (ruim em $\mathrm{PE}, \mathrm{OK}$ em $\mathrm{PB}$ )

(11) a. O Paulo é sempre simpático. (OK em PE, OK em PB)

b. O Paulo é simpático sempre. (ruim em PE, OK em PB)

(12) a. O Paulo conhece a Maria bem mesmo sem nunca ter visto (OK em PE, ruim em PB: comparar com “... sem nunca ter visto ela”)

b. O Paulo conhece bem a Maria mesmo sem nunca ter visto (ruim em PE e em PB: de novo, comparar com "... sem nunca ter visto ela") (Para um exemplo de construção de lacuna parasita em PB: "Que pessoa o Paulo conheceu bem sem nunca ter encontrado ?)

Em resumo, a linha de argumentação por analogia com scrambling em holandês e alemão não se estende ao $\mathrm{PB}$, pelo menos.

A segunda linha de argumentação é a que mais interessa neste trabalho, porque é ela que aponta para relevância da interface entre sintaxe e prosódia. Por essa linha, João Costa procura mostrar que, ao contrário do que se postulava tradicionalmente e do que Pollock (1994) argumentou para o inglês, a ordem [V Adjunto Complemento] não pode ser derivada de (5) por movimento à direita do complemento, como representamos em (13):

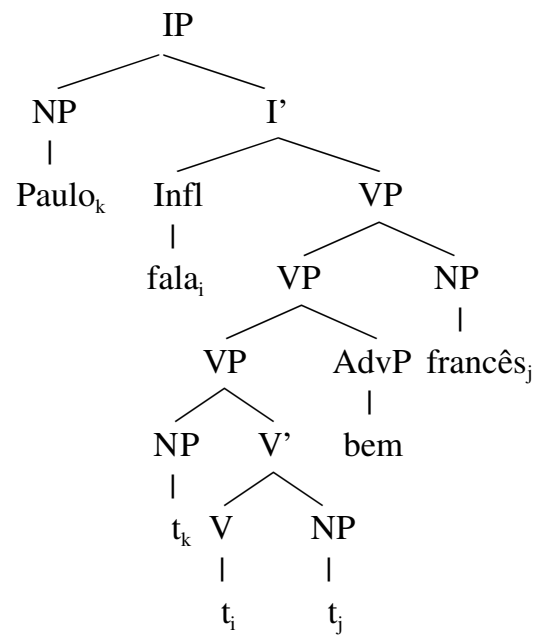


O ponto central do debate com Pollock reside na explicação para a adjacência estrita que há entre o V e o NP objeto em inglês (cf. COSTA, 1998, p.29 e ss.). Como se sabe, para Pollock, essa adjacência se deve ao fato de que o V não se move para fora do VP em inglês. Para João Costa, entretanto, a adjacência tem outra explicação: resulta do fato de o verbo se mover, em inglês, para uma posição funcional imediatamente superior a AgrO, e do NP objeto necessariamente mover-se para Spec-de-AgrO (cf. também JOHNSON, 1991, e outros). O principal argumento para essa análise é um fato bem conhecido: não existe o requisito de adjacência em inglês para complementos que são PPs (cf. (15) e (16), por exemplo). Como PPs não precisam se mover para Spec-de-AgrO para receber Caso, podem ficar em sua posição de base, e a ordem [V Adv PP] é permitida.

Para Pollock, por outro lado, o que mostra que é uma derivação como (13) que está por trás da ordem [V Adv PP] em inglês é que essa ordem só é possível com adjuntos/advérbios que podem, independentemente, ocorrer à direita do VP (exemplos adaptados a partir de J. Costa, 1998, p.31):

(14) a. Bill (hardly) knocked (*hardly) on it (*hardly)

b. Harry (sure) relies (*sure) on Mary (*sure)

(15) a. Bill (carefully) knocked (carefully) on it (carefully)

b. Harry (frequently) relies (frequently) on Mary (frequently)

João Costa, por sua vez, assume que as posições pós-verbais dos advérbios em (15) resultam exatamente dos mesmos processos que atuam em PE: (a) movimento de $\mathrm{V}$ (para AgrO em inglês) por sobre o advérbio, necessariamente adjunto à esquerda do VP, o que resulta na ordem [V Adv COMPL]; e (b) scrambling do complemento por sobre o advérbio, o que resulta na ordem [V Compl ADV]. Advérbios sentenciais como hardly e sure não podem ocupar posições pós-verbais porque estas são sempre posições de adjunção à esquerda do VPe advérbios sentenciais não podem se adjungir ao VP. ${ }^{5}$

O principal argumento de João Costa contra a análise de Pollock para casos como (15) reside no comportamento de uma classe específica de advérbios, que passa a ser nosso objeto principal de discussão a partir de agora. ${ }^{6}$ João Costa os identifica como a classe dos advérbios monossilábicos: advérbios como well, hard, fast em inglês, e bem, mal e, talvez, já em português. Esses advérbios podem ocorrer na posição pós-verbal intermédia 
entre o verbo e o PP complemento (frases (a) em (16)), mas ou são excluídos ou fortemente desfavorecidos na posição final (frases (b)); nesta posição, só podem ocorrer se estiverem sob "heavy stress" (p.37), ou, em outros termos, se forem "prosodically marked" (p.103) (frases (c) em (16); exemplos - e juízos para o português - nossos):

(16) i. a) John looked well at the picture

João olhou bem pro retrato

b) * John looked at the picture well

??João olhou pro retrato bem

c) John looked at the picture WELL

João olhou pro retrato BEM

ii. a) João argumentou mal contra a tua posição

b) ??João argumentou contra a tua posição mal

c) João argumentou contra a tua posição MAL

Assim, João Costa sugere que esses advérbios só ocorrem em posição final em último recurso, e isso ficaria inexplicado se sua posição "normal", de base, fosse a adjunção à direita do VP, como em (13). Portanto, a posição de base dos advérbios monossilábicos é necessariamente a de adjunção à esquerda do VP, e a ordem [V Adv PP] resulta de movimento do V para fora do VP em inglês. A estrutura "mais marcada" [V PP Adv] (ou [V NP Adv]) exige uma operação adicional, de scrambling, motivada pela necessidade do advérbio a ser focalizado.

É importante assinalar, neste ponto, que a idéia de que o que "motiva" a posição final dos advérbios monossilábicos é sua "focalização" pode estar incorreta. Sem qualificações, isso prediz que eles devem se localizar entre o verbo e o complemento não apenas quando o foco está no complemento, mas em qualquer situação em que eles próprios não sejam o foco da frase. Essa predição, entretanto, parece não se confirmar, pelo menos para o PB. Para nós, um advérbio monossilábico pode se localizar após o complemento, em posição final de frase, quando o foco é o sujeito da sentença encaixada, como em (17i.a), ou quando toda a sentença (encaixada) é foco, como em (17ii.a): 
(17) i. A: Você sabe de alguém que fale francês?

B: a) Já ouvi dizer que a MARIA fala francês bem.

b) ? Já ouvi dizer que a MARIA fala bem francês.

ii. A: O que o João disse?

B: a) Ele disse que a Maria fala francês BEM.

b) ??Ele disse que a Maria fala bem FRANCÊS.

Não tentaremos discutir em detalhe a interpretação informacional dessas e das demais estruturas que analisaremos a seguir. (Casos como (17ii), por exemplo, exigiriam que considerássemos o fenômeno da "projeção do foco", cuja literatura é abundante.) Mas reiteramos: casos como (17) indicam que não há razão para assumir que, em PB, os advérbios monossilábicos sejam necessariamente "focalizados" em posição final, nem que a estrutura resultante seja "informa-cionalmente marcada". Em nossa análise, a restrição que atua ocasionalmente nesses casos é de natureza puramente prosódica, e não requer que a posição final para advérbios monossilábicos seja sintática ou informacionalmente "marcada".

Lembremos, entretanto, que, numa abordagem como a sugerida por Cinque, prosódia e sintaxe mantêm uma relação mais direta entre si; parece natural, portanto, admitir que a distribuição relativamente limitada dos advérbios monossilábicos, ainda que condicionada fonologicamente, seja reflexo de uma posição sintaticamente fixa. Assim, esses advérbios se tornam muito importantes para João Costa, que os toma como diagnóstico para identificar a posição dos demais constituintes na frase: todos os que estão à esquerda de um advérbio monossilábico estão em alguma posição acima de VP; todos os que estão à direita, estão em uma posição interna ao VP (cf. COSTA, 1998, p.39; ver especialmente o capítulo 3, onde os monossilábicos são utilizados várias vezes para identificar a posição do sujeito e do objeto à direita do verbo em PE).

Mas a questão central - aquela que interessará daqui em diante - é: qual a restrição fonológica específica que faz com que os advérbios monossilábicos possuam uma distribuição tão limitada, em oposição aos demais advérbios que pertencem à mesma classe semântica (dos advérbios de modo)? Como João Costa aponta, as razões são muito provavelmente de natureza prosódica; e, como procuraremos mostrar, têm conseqüências para o modo como devemos conceber a relação entre sintaxe e prosódia. 


\section{ADVÉRBIOS MONOSSILÁBICOS E SINTAGMAS FONOLÓGICOS}

Pode-se identificar, na discussão realizada por João Costa, três argumentos para sustentar que a restrição na distribuição dos advérbios monossilábicos está relacionada com a prosódia: (a) o que caracteriza a classe não é sua categoria semântica mais geral, mas sua constituição silábica, uma propriedade fonológica sabidamente relevante para a organização prosódica da frase; (b) o fato de que podem ocupar a posição final em caso de receberem um acento marcado (cf. (16c)) também indica que o problema em (16b) está na integração prosódica do advérbio à frase, que pode ser obtida por uma "operação prosódica de último recurso"; (c) confirmando o fato de que a restrição está relacionada à constituição silábica do advérbio, os mesmos advérbios, quando modificados - e, portanto, tornados mais complexos silábica e prosodicamente - podem ocupar a posição final, como os demais advérbios de modo, como em (18b) e (19b):

(18) a. ??João olhou pro desconhecido bem; por isso, conseguiu reconhecê-lo nas fotos.

b. João olhou pro desconhecido muito bem; por isso, conseguiu reconhecê-lo...

(19) a. ??João argumentou contra a tua posição mal; ele podia ter mostrado que...

b. João argumentou contra a tua hipótese muito mal; ele podia...

Uma outra observação de João Costa pode ser interpretada como um argumento a favor do condicionamento prosódico na distribuição dos advérbios monossilábicos em inglês: quando o complemento é um NP, o advérbio só pode ocorrer depois dele, justamente a posição desfavorecida quando se trata de PPs.

(20) a. John looked well at the picture.

a'. * John looked at the picture well.

b. * John speaks well French.

b'. John speaks French well.

Segundo se infere da discussão, well é obrigado a "tolerar" a posição final em (20b’) porque não há outra posição possível em inglês, em virtude do movimento obrigatório do NP para Spec-de-AgrO. Em PE, justamente 
porque o movimento do NP é scrambling, isto é, adjunção ao VP (e não movimento obrigatório para efeitos de Caso, como o movimento para Specde-AgrO em inglês), é possível ter ambas as ordens (dependendo do foco da frase, cf. (1) e (2)). Entretanto (e aqui, a nosso ver, revela-se o condicionamento prosódico desse contraste), mesmo em $\mathrm{PE}$ e $\mathrm{PB}$, há diferença de aceitabilidade conforme o elemento interveniente seja um NP ou um PP (para o PE, ver COSTA, 1998, p.158-9):

(21) a. João fala francês bem.

b. ??João olhou pro retrato bem.

(22) a. João entendeu Maria mal.

b. ??João argumentou contra a tua posição mal.

Em (21a) e (22a), segundo João Costa, o movimento do NP é de scrambling; portanto, não se pode apelar para a ausência de uma derivação sintática alternativa como razão para o contraste de aceitabilidade entre as frases em (21) e (22). Há, entretanto, uma explicação prosódica para ele: a operação de "reanálise" de sintagmas fonológicos, que mencionamos na discussão de (8) e (9) apresentados anteriormente.

Como mostramos, a regra de construção de sintagmas fonológicos proposta por $\mathrm{N} \& \mathrm{~V}$ tem como finalidade básica formar um constituinte prosódico a partir de um núcleo lexical e todos os seus "dependentes semânticos" à esquerda (cf. (8)). Contudo, sintagmas fonológicos pertencem à hierarquia superior da prosódia da frase e, por isso, devem ter uma constituição minimamente complexa - algum grau de ramificação prosódica para poderem ser constituídos. Para dar um exemplo, reconsidere (9), aqui repetida:

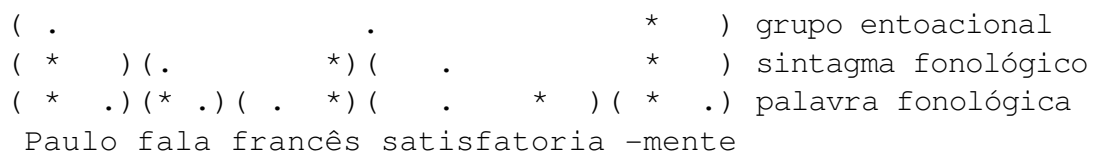

O agrupamento prosódico mais natural da frase em (9) coloca o verbo fala e o substantivo francês num mesmo sintagma fonológico. No entanto, pela regra apresentada em (7a), fala e francês deveriam cada um formar um sintagma fonológico separado. O que permite que sejam unidos num só? Intuitivamente 
falando, o que acontece é que ambos apresentam complexidade ou ramificação prosódica relativamente pequena e podem, portanto, ser agrupados em um único sintagma prosódico. Adaptando ligeiramente a regra proposta por $\mathrm{N} \& \mathrm{~V}$ (1986, p.173), podemos formular o processo de reanálise do seguinte modo:

(23) Reestruturação de sintagmas fonológicos (opcional):

Um sintagma fonológico não-ramificado $\phi$ ' que é o primeiro modificador de $\mathrm{X}$ à direita pode ser integrado ao $\phi$ de $\mathrm{X}$.

Com (23), fica claro por que os agrupamentos prosódicos em (9) são do jeito que são: francês conta como "não-ramificado" para os fins de (23) e, sendo um modificador do verbo fala, pode ser reanalisado como parte do $\phi$ deste. ${ }^{7}$ Note-se ainda que não há outra segmentação prosódica natural para (9). De fato, pela análise desenvolvida até aqui, (9) não pode, por exemplo, ser segmentada prosodicamente como "(Pàulo fála) (francès satìsfatoriaménte)" (onde o acento grave “" representa acentos secundários, e o agudo “””, os acentos frasais): embora a regra de formação de $\phi$ 's em (7a) permita integrar Paulo ao $\phi$ de fala, a regra de reanálise em (23) não permite juntar francês e satisfatoriamente em um único $\phi$ (já que satisfatoriamente não é um modificador de francês). ${ }^{8}$

Considere-se, agora sob essa ótica, o contraste entre PPs e NPs com relação à possibilidade de os advérbios monossilábicos ocorrerem em posição final, ilustrado em (21) e (22): o padrão pode perfeitamente ser reduzido aos efeitos da regra em (23) se, adicionalmente, supusermos que (23), na verdade, atue para reajustar segmentações que não satisfazem a seguinte condição de boa-formação prosódica:

Complexidade Rítmica Mínima:

Todo sintagma fonológico deve ser minimamente ramificado (prosodicamente).

É fácil de compreender intuitivamente a natureza de (24): sintagmas fonológicos são constituintes da estrutura superior da prosódia da frase; são, em particular, os constituintes a partir dos quais o ritmo da frase se organiza em termos de acentos frasais (secundários e primário, ou nuclear - atribuídos por (7b) e (7c), respectivamente). Obviamente, para haver alternância rítmica entre os acentos frasais de dois sintagmas fonológicos contíguos, é preciso que haja algum material fonológico menos proeminente entre ambos os acentos. Por exemplo, 
tomemos as sílabas, as unidades prosódicas básicas, como as unidades com base nas quais a noção de "ramificação" relevante a (24) é definida: nesse caso, (24) terá como efeito identificar uma seqüência ... [s.śs] [s.śs] ... como ritmicamente bem-formada, e uma seqüência ... [s.śs] [śs]... como malformada. Em outras palavras, nesse caso concreto, (24) tem como efeito básico que sintagmas fonológicos devem ser minimamente constituídos de duas sílabas, e atua contra sintagmas fonológicos monossilábicos. ${ }^{9}$

Considere agora (21a): das várias possibilidades de organização prosódica em (25), a mais natural é, nos parece, é (25d), sendo as demais, em diferentes graus, desfavorecidas:
a. ?? (Joáo) (fála) (francés) (bém)
b. * (Joào fála) (francès bém)
c. ? (Joáo) (fàla francés) (bém)
d. (Joáo) (fàla frances bém) $)^{10}$

Embora (25a) esteja de acordo com o algoritmo de formação de sintagmas prosódicos proposto por $\mathrm{N} \& \mathrm{~V}$, é desfavorecida porque apresenta vários sintagmas prosódicos com pequena complexidade rítmica, o que resulta em baixa integração prosódica do material fonológico (efeito contra o qual algo como (23) deveria atuar, embora (23), do modo como a formulamos, não o faça). (25b) resolveria esse problema; entretanto, o sintagma fonológico (francès bém) não pode ser construído, seja pela regra regular de formação de $\phi$ 's em (7a), seja por meio da regra de reestruturação em (23). (25c), por outro lado, resulta da aplicação da regra regular de formação de $\phi$ 's juntamente com a reanálise de francês como parte do $\phi$ de fala. O padrão acentual é "marcado" e corresponde, parece-nos, aos casos em que João Costa diz que o advérbio monossilábico, em posição final, recebe "acento pesado". Na configuração em (25c), fica claro o que significa esse "acento pesado" e por que ele é "marcado": o acento é pesado não apenas porque é o acento nuclear da frase, mas porque ocorre num sintagma prosódico sem estrutura apropriada para integrar-se à organização rítmica da frase. Em nossa análise, bem formando um sintagma prosódico por si próprio viola a restrição em (24).

Finalmente, consideremos (25d), que é, para nós, a configuração prosódica na qual os advérbios monossilábicos são mais bem aceitos em posição final com um NP intervindo entre eles e o verbo. Por que essa 
configuração é menos marcada? Em nossa análise, porque nela bem não é um constituinte prosódico por si próprio, mas foi integrado a outro sintagma fonológico, permitindo uma melhor organização rítmica. Mas como essa melhor organização prosódica pode ser obtida? Pela aplicação sucessiva da regra de reestruturação em (23): francês pode ser integrado ao sintagma fonológico de fala porque é "não-ramificado" no sentido relevante de (23) e é "modificador" à direita de fala; uma vez constituído este sintagma fonológico, a regra de reestruturação pode se aplicar novamente a bem: é também um sintagma fonológico "não-ramificado" e é modificador à direita de fala.

Em suma, advérbios monossilábicos são "desfavorecidos” em posição final porque, pela operação da regra regular de formação de $\phi$ 's, teriam que formar um sintagma fonológico por si próprios; no entanto, não possuem constituição prosódica satisfatória para isso, como estabelecido em (23). Há, por outro lado, a possibilidade de ocuparem a posição final se puderem ser integrados a algum outro sintagma fonológico; e isso acontece se o NP objeto for "pouco ramificado prosodicamente", caso em que a regra (recursiva) de reestruturação de sintagmas prosódicos poderá se aplicar novamente.

Nessa perspectiva, é possível compreender por que os advérbios monossilábicos são quase que invariavelmente marcados quando o complemento interveniente é um PP (cf. (21b) e (22b)). PPs são, geralmente, "ramificados" e, por isso, normalmente bloqueiam a operação da regra de reestruturação em (23): uma vez que os PPs não são integrados ao sintagma fonológico do verbo, eles acabam se constituindo numa barreira que impede que o advérbio se integre ao verbo. A saída seria integrar o advérbio ao PP, mas a operação também não é permitida, seja pela regra regular de formação de ф's em (7a) (o PP está à esquerda do advérbio, mas não é um modificador dele), seja pela regra de reestruturação em (23) (o advérbio é "não-ramificado" e está à direita do PP, mas não é um modificador dele). Assim, só resta ao advérbio formar sozinho um sintagma fonológico, como acontece em (25c). Mas, nesse caso, de novo temos o sintagma fonológico com que recebe o acento nuclear da frase pouco integrado à sua estrutura rítmica e, por isso, a estrutura inevitalmente marcada de casos como (21-22b).

Finalmente, essa forma de tratar o assunto permite também explicar por que os demais advérbios de modo e mesmo os advérbios monossilábicos, quando modificados, podem ocorrer sob o acento nuclear em posição final, como em (26): 
(26) a. (Joáo) (fàla francés) (satìsfatòriaménte)

b. (Joáo) (fàla francés) (mùito bém)

A razão é simples: em ambos os casos, há material fonológico suficiente para a constituição independente do sintagma fonológico que receberá o acento nuclear.

\section{OUTRAS EVIDÊNCIAS}

Assim, uma razão muito plausível para a distribuição limitada dos advérbios monossilábicos (em particular, o fato de que "não gostam" da posição final da frase em alguns casos) é puramente fonológica: eles não possuem conteúdo fonológico suficiente, nos contextos pertinentes, para a constituição de um sintagma fonológico. Essa explicação é natural: uma propriedade fonológica desta classe de advérbios - a de serem monossilábicos - faz com que tenham distribuição limitada em função da estrutura prosódica da frase.

Nessa explicação, não há apelo direto a conceitos sintáticos. A sintaxe entra na explicação apenas indiretamente. Primeiro, por meio da distribuição dos advérbios de modo, que, por sua natureza sintático-semântica, ocorrem em certas posições (por hipótese, a posição de base é a de adjuntos a VP). Advérbios de modo monossilábicos ocorrerão em um subconjunto dessas posições, já que estão sujeitos a uma condição adicional: a posição deve permitir que sejam integrados a um sintagma fonológico. Segundo, por meio das regras de formação e reestruturação dos sintagmas fonológicos, que são sensíveis a informações sintático-semânticas relativamente genéricas (em particular, às noções de núcleo lexical e de modificadores do núcleo, i.é, elementos relacionados sintaticamente com o núcleo, tais como especificadores, complementos, adjuntos). Em particular, é importante ressaltar que, nessa concepção, há alguma correspondência entre constituintes prosódicos e sintáticos, mas ela é parcial, resultante do fato de que sintagmas prosódicos não são reflexos diretos dos sintagmas sintáticos, mas são definidos a partir de informações sintáticas genéricas.

Qual é a propriedade fonológica dos advérbios monossilábicos que determina a sua distribuição e como se relaciona ela com a sintaxe? Para Costa (1998), o fundamental é que, sendo monossilábicos, são palavras "leves demais 
para sustentar o acento principal por default", razão pela qual "elas são desfavorecidas na posição sintática em que o acento da frase cai" (p.39). Deixando de lado, temporariamente, a questão de saber se a propriedade fonológica identificada está correta, neste trecho o raciocínio é semelhante ao que desenvolvemos: por causa de suas propriedades fonológicas, advérbios monossilábicos possuem uma distribuição restrita. Adiferença: essa "restrição" se reflete diretamente na sintaxe e faz com que os advérbios só ocorram numa única posição sintática - como adjuntos à esquerda de VP - na qual, na maioria dos casos, podem evitar a posição de acento nuclear no final da frase. $\mathrm{Na}$ abordagem que estamos sugerindo, a distribuição restrita dos monossilábicos deve ser caracterizada diretamente em termos prosódicos e não fornece evidência direta para estabelecer suas possíveis posições sintáticas. Estabelecer as posições sintáticas é matéria de sintaxe-semântica e, SMJ, advérbios como bem e mal deveriam poder, dessa perspectiva, ocupar exatamente as mesmas posições que muito bem e muito mal.

Quanto à análise das propriedades fonológicas relevantes de bem e mal, é importante enfatizar que, para João Costa, esses advérbios são desfavorecidos na posição final - o que motivaria sua adjunção à esquerda - por serem "leves" demais para receber acento nuclear por default. Há, entretanto, razões para acreditar que esse ponto da análise não está correto.

A primeira delas é que advérbios como bem e mal não são palavras átonas, mas tônicas, isto é, possuem acento lexical primário (ainda que, possivelmente, em pé degenerado porque constituído de uma única sílaba). Assim, não há impedimento algum, em princípio, para que portem acento. A restrição, então, teria de ser - como João Costa a formula - de portar acento nuclear.

Entretanto, como o próprio João Costa observa, os advérbios monossilábicos também podem portar acento nuclear, como acontece em estruturas com NPs complementos (em, por exemplo, "John speaks French well"). Pode-se argumentar que, nesses casos, é necessário recorrer a alguma estrutura prosódica marcada; mas, em outros contextos, não cremos que isso seja sustentável. Por exemplo, a palavra bem é freqüentemente utilizada como um marcador discursivo e neste uso ocorre como grupo entoacional independente, portanto, carrega acento nuclear próprio:

(27) A: (...) O que você acha disso?

B: Bem... não sei se devo me meter nisso... 
Um contexto ainda mais claro é aquele em que o VPé constituído apenas pelo verbo e pelo advérbio: nesses casos, ambos podem formar um sintagma fonológico, e o advérbio recebe acento nuclear final muito naturalmente:

A: Puxa, você 'tá com uma cara... O que aconteceu?

B: (Meu fillho pequéno) (dormìu mál).

(29) A: Por que o João anda com aquele sorriso largo?

B: É que ele aplicou na bolsa e (se dèu bém).

Em nossa proposta, não há nada de excepcional em casos como (28) e (29): são casos análogos à estrutura prosódica que faz com que esses advérbios sejam naturais na ordem [V Adv COMPL]. Na configuração em (28)-(29), os advérbios monossilábicos não precisam formar um sintagma prosódico sozinhos, podendo fazer parte do sintagma fonológico do verbo, integrandose à cadeia rítmica do enunciado. Crucialmente, para nós, há uma diferença entre a ordem [V Adv COMPL] e os casos em (27) e (28)-(29): nestes últimos, os advérbios recebem o acento nuclear da frase, o que mostra que não há nada que os desfavoreça como portadores desse acento.

Outros casos mostram que mesmo a adjacência ao verbo é desnecessária para que os advérbios monossilábicos sejam apropriadamente integrados à prosódia da frase em posição de acento nuclear. Aparentemente, a adjacência só é necessária quando eles precisam ser integrados ao sintagma fonológico do verbo. Os casos relevantes são aqueles em que o advérbio não é interpretado apenas como modificador do verbo, mas é também, na função de predicativo, relacionado semanticamente ao complemento, como em (30) e (31):

(30) a. Quando soube do acidente, João correu pra casa. Mas nada tinha acontecido: chegando lá, (èncontróu) (tòdo mùndo bém).

b. ?? ..., (èncontròu bém) (tòdo múndo).

(31) a. João viveu como um playboy, gastou todo dinheiro que tinha guardado, e, quando faleceu, (dèixóu) (à famìlia mál)

b. ..., (deixòu mál) (à família).

Pondo de lado uma discussão mais detalhada desses exemplos (e do modo como devem ser incorporados à regra de formação de sintagmas fonológicos), o ponto fundamental é: a relação predicativa que bem e mal têm 
com o complemento parece autorizar que constituam um sintagma prosódico com o complemento sem necessariamente incorporar o verbo. Nesses casos, os advérbios monossilábicos podem ocorrer naturalmente na posição final, com o acento nuclear da frase.

Em suma, há evidência clara de que não há uma restrição geral seja contra a atribuição de acento nuclear aos advérbios monossilábicos, seja contra sua ocorrência em posição final de enunciado; as restrições observadas por João Costa parecem ter a ver com o modo como esses advérbios podem se agrupar, prosodicamente, com outros elementos da frase. Uma outra predição feita por nossa abordagem é que o contraste entre NPs e PPs complementos com relação à possibilidade de advérbios monossilábicos ocorrerem em posição final não é a generalização correta; o que deveria, de fato, ocorrer é um contraste entre estruturas mais ou menos ramificadas prosodicamente; deveria haver, por exemplo, diferença de aceitabilidade entre NPs pouco ramificados, como os apresentados por João Costa, e NPs mais ramificados. Observe o contraste entre (32) e (33):

(32) A: Eu soube que o João fala francês apenas pra quebrar o galho. E os demais rapazes da turma?

B: (Que eu saiba,) o irmão dele fala francês bem.

(33) A: Eu soube que o João fala francês apenas pra quebrar o galho. E os demais rapazes da turma?

B: ? (Que eu saiba,) o irmão dele fala várias línguas bem.

Para nós é difícil detectar diferença significativa entre os dois casos, embora possivelmente haja um pequeno contraste na direção indicada. De qualquer modo, além do contraste entre NPs “curtos" e NPs "longos", esperarse-ia também a contraparte desse contraste com PPs, como em (34) versus (35):

(34) A: Puxa, mas não era a Maria quem tinha a grana? Como o João ficou depois da separação?

B: Ah, ele conseguiu sair dessa bem: ficou com o apartamento em que eles moravam.

(35) A: Puxa, o João sempre se dá mal na hora de se separar...

B: ? Nem tanto... Ele conseguiu sair da última separação bem: ... 
De novo, para nós, o contraste é difícil de detectar; além disso, em (34) e (35) a ordem preferencial é [V Adv Compl]. A dificuldade de identificar contrastes sutis como os entre (32) e (33), e entre (34) e (35), não nos impede de apontar que aqui há uma diferença entre as duas análises que é verificável empiricamente: pela análise que sugerimos, deve-se esperar, num estudo de corpus, por exemplo, uma correlação entre a extensão fonológica/prosódica do complemento, e a possibilidade de o advérbio monossilábico ocorrer em posição final: quanto mais extenso o complemento interveniente entre o verbo e o advérbio, menor a probabilidade de ocorrência do advérbio em posição final. Evidentemente, essa predição não pode ser feita na teoria adotada por João Costa.

Para encerrar a discussão sobre as diferenças empíricas entre as duas análises, apontamos uma última: como a restrição que assumimos (i.é, (24)) não é específica aos advérbios monossilábicos, mas está relacionada com uma propriedade geral de palavras monossilábicas - a de que não possuem conteúdo fonológico suficiente para formar um sintagma fonológico -, esperase que a mesma restrição seja encontrada em outros casos. Por exemplo, ela deveria também se aplicar a complementos monossilábicos. De fato, esse parece ser o caso em (36):

(36) A: Quantos livros o João comprou na semana passada?

B: a) (Que eu saiba,) ele só comprou um na semana passada.

b) ??(Que eu saiba,) ele só comprou na semana passada um.

(37) A: Eu sei que o João gostou da visita que fez a São Paulo... Mas onde ele pretende morar no ano que vem?

B: a) (Que eu saiba,) ele pretende morar lá no ano que vem.

b) ??(Que eu saiba,) ele pretende morar no ano que vem lá.

As considerações de caráter prosódico que tecemos aqui podem ser, ainda, estendidas a casos de sujeitos pós-verbais leves que tendem a ficar adjacentes ao verbo, como vemos em (38) (como os resultados de Fernandes 2005 também indicam):

(38) a. Já morreu gente na montanha russa.

b. * Já morreu na montanha russa gente.

c. ?Já morreu na montanha russa muita gente. 
Para resumir: ainda que alguns dos contrastes preditos pela análise aqui esboçada não sejam nítidos, parece claro que há evidência satisfatória indicando que: (a) não há restrição que penalize a atribuição de acento nuclear aos advérbios monossilábicos, (b) nem há restrição que penalize, como regra geral, sua ocorrência em posição final de frase; antes, parece mais provável que (c) esses advérbios têm problemas na posição final quando, por algum motivo (por exemplo, se o complemento interveniente é "ramificado demais"), não podem ser apropriadamente integrados a um sintagma fonológico maior que o formado apenas por eles.

\section{CONCLUSÃO}

Neste trabalho, procuramos mostrar que as restrições que encontramos na distribuição dos advérbios monossilábicos em $\mathrm{PB}$ recebem uma análise natural se o que está em jogo é a formação de sintagmas fonológicos. A evidência que apresentamos indica que não há restrição específica seja contra sua ocorrência em posição final de frase, seja contra a possibilidade de que carreguem o acento nuclear da frase. Esta última conclusão, em particular, é crucial aqui, já que nosso objetivo era justamente avaliar a evidência disponível para a sintaxe do lado direito: o fato de que os advérbios monossilábicos podem portar o acento nuclear da frase enfraquece substancialmente - ao menos para o PB - a motivação oferecida por João Costa (1998) para postular a adjunção à esquerda do VP como uma posição fixa para eles. Lembramos que a relevância disso reside na possibilidade de utilizar os advérbios monossilábicos como diagnóstico para a identificação da posição de outros elementos na frase, no caso de terem de fato uma posição fixa.

Se é verdade que os advérbios monossilábicos podem portar o acento nuclear da frase, então a necessidade de sua adjunção à esquerda do VP não pode ser motivada com base em uma estratégia para evitar justamente que carreguem o acento nuclear. Do ponto de vista da análise aqui defendida, a hipótese deveria ser reformulada nos seguintes termos: advérbios monossilábicos favorecem a posição de adjunção à esquerda do VP porque nela podem fazer parte do sintagma fonológico que melhor os integra à prosódia da frase. Entretanto, como procuramos mostrar, não é óbvio que a formação de sintagmas fonológicos precise da adjunção à esquerda do VP. Na versão de N\&V (1986), por exemplo, isso não é necessário, nem o seria 
em outras análises mais recentes da correspondência entre constituintes sintáticos e prosódicos (ver, por exemplo, Samek-Lodovici, 2005, para observações no mesmo sentido). Assim, para sustentar que a adjunção dos advérbios monossilábicos à esquerda do VP é motivada por suas "propriedades prosódicas", seria preciso desenvolver uma teoria da formação dos sintagmas prosódicos em que aquela posição fosse crucial para integrálos ao sintagma prosódico do verbo. Até o presente, entretanto, essa teoria ainda não foi formulada.

Além disso, é importante lembrar que a idéia de que os advérbios monossilábicos seriam necessariamente adjuntos à esquerda de VP é parte importante da argumentação de João Costa a favor da hipótese de que a ordem [V Compl Adv] é derivada por scrambling do complemento. Recapitulemos o raciocínio: (a) na ordem [V Compl Adv], os advérbios monossilábicos recebem o acento nuclear e são focalizados em português (embora esta seja uma estrutura prosodicamente marcada); (b) para receberem o acento nuclear segundo a teoria de Cinque (1993), precisam estar na posição mais encaixada da frase; (c) isso se segue naturalmente se os advérbios monossilábicos estão necessariamente adjuntos à esquerda do VP: neste caso, há scrambling do complemento, e os advérbios monossilábicos se tornam os constituintes mais encaixados da frase.

O ponto fundamental é que uma análise com scrambling e a adjunção à esquerda dos advérbios monossilábicos é compatível com a teoria de Cinque para a atribuição do acento nuclear; por contraste, uma análise com a adjunção à direita, como em (5), não é. Dessa forma, pode-se ver a distribuição dos advérbios monossilábicos como um argumento para a derivação sintática proposta em (6) se for necessário admitirmos a teoria de Cinque para o acento nuclear. Mas ela é necessária, ou geralmente assumida, em estudos de prosódia? Como indicamos antes, a idéia corrente em fonologia é a de que o acento nuclear é atribuído em função da estrutura prosódica/grade métrica da frase, que é construída com relativa autonomia em relação à estrutura sintagmática. Em Selkirk (1984, 1995), N\&V (1986), Truckenbrodt (1999), entre outros, ela certamente não é um reflexo direto da estrutura sintagmática, como na teoria de Cinque.

Na verdade, há aqui um argumento contra a teoria de Cinque para a atribuição do acento nuclear: (a) como procuramos mostrar, uma teoria fonológica da estrutura prosódica que caracteriza os agrupamentos a partir dos 
quais o ritmo acentual da frase é identificado pode também caracterizar a localização do acento nuclear; (b) entretanto, uma teoria como a de Cinque, desenhada especificamente para ligar o acento nuclear à estrutura sintática, não pode dispensar uma teoria independente da construção da estrutura prosódica da frase.

De fato, como na teoria de Cinque a atribuição de acentos reflete, simplesmente, o nível de encaixamento dos constituintes, o resultado é que nem sempre a análise é capaz de identificar os constituintes que caracterizam a curva rítmica da frase. ${ }^{11}$ Para ver isso, considere qual seria a grade métrica construída pela teoria de Cinque para uma frase como "Paulo fala bem francês", de acordo com a análise sintática proposta por João Costa (ver (4), e CINQUE, 1993, p.244-246 para detalhes):

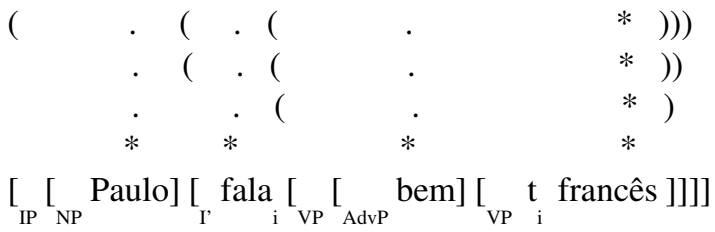

É claro que essa grade métrica nem representa os agrupamentos prosódicos mais naturais (por exemplo, bem aparece agrupado com francês, e não com fala), nem a localização correspondente dos acentos secundários; como já discutimos antes, a representação prosódica da frase deveria ser capaz de caracterizar os seguintes agrupamentos, com acento nuclear em francês (sinalizado por negrito no próximo exemplo):

(40) (Páulo) (fàla bém) (fràncés)

Talvez seja bom lembrar que a justificativa para a formação dos sintagmas prosódicos em (40) vem não apenas da localização de acentos, mas de várias outras regras fonológicas encontradas em diferentes línguas (como o Raddoppiamento Sintattico em italiano; ver, mais uma vez, N\&V 1986). Parece claro, portanto, que a teoria de Cinque precisará de instrumentos adicionais, especialmente para caracterizar os sintagmas fonológicos da frase, ou seja, ela não pode dispensar algum algoritmo adicional de formação desses sintagmas. Mas, se esse algoritmo pode, simultaneamente, localizar o acento nuclear da frase, é claro que a teoria de Cinque perde muito do seu apelo. 
Para este trabalho, o ponto fundamental é: é provável que a teoria de Cinque para o acento nuclear precise ser subsumida por uma teoria mais abrangente da estrutura prosódica da frase, mais autônoma em relação à sintaxe. Se isso é verdade, também o argumento de que a análise sintática correta da ordem [V Compl Adv] em português deve ser compatível com essa teoria perde apelo; em particular, fica claro que a análise baseada na operação de scrambling do complemento precisa de justificativa independente e não pode se apoiar na correção da teoria de Cinque para o acento nuclear. Isso não significa que a ordem [V Compl Adv] em PB não envolva simultaneamente scrambling do complemento e adjunção do advérbio à esquerda do VP, como João Costa propôs para o PE. Significa, simplesmente, que nem o comportamento dos advérbios monossilábicos, nem a atribuição de acento nuclear baseada na teoria de Cinque (1993), fornecem evidência satisfatória para essa análise em PB.

De um ponto de vista mais positivo, gostaríamos de fechar este trabalho apontando para o fato de que, se a linha de análise que sugerimos para a distribuição dos advérbios monossilábicos em PB estiver correta, ela fornece uma evidência muito forte para a maior autonomia da fonologia em relação à sintaxe no que diz respeito à organização prosódica da frase. Precisamente como esta relação entre os dois componentes deve ser expressa, entretanto, é uma contribuição que escapa a nossos objetivos aqui.

\section{NOTAS}

${ }^{1}$ O presente artigo é o resultado de um diálogo que iniciou com a discussão, pelo segundo autor, do trabalho apresentado pelo primeiro no Encontro de Ouro Preto. Queremos agradecer às outras vozes que participaram, ainda que menos intensamente, desse diálogo - os colegas do GT de Gramática presentes àquele encontro.

${ }^{2}$ A hipótese da correspondência parcial entre constituinte sintáticos e prosódicos possui formulações mais recentes, baseadas na idéia de alinhamento das fronteiras desses constituintes; ver Ghini (1993), Selkirk (1995) e Truckenbrodt (1999, 2005); para o PB, ver Sandalo \& Truckenbrodt (2002). Esses trabalhos, entretanto, conservam as intuições básicas da abordagem de $\mathrm{N} \& \mathrm{~V}$ (a correspondência entre constituintes sintagmáticos e prosódicos é indireta, e a atribuição de acentos é baseada em constituintes prosódicos). Assim, preferimos aqui evitar a apresentação de assunções menos pertinentes a nossa discussão (por exemplo, relativas à teoria da otimidade), adotando a versão que aparece em (7) da análise, relativamente ultrapassada, de $\mathrm{N} \& \mathrm{~V}$. 
${ }^{3}$ Para bem da exatidão, algumas observações sobre nossa análise informal em (7) são necessárias.

Numa formulação mais fiel à de $\mathrm{N} \& \mathrm{~V}$, a cláusula correspondente a (7a.ii) diria: "todo constituinte à esquerda $\mathrm{X}$ até o $\phi$ ' que contenha um núcleo lexical $\mathrm{Y}$ que esteja fora da projeção máxima de X". Nossa versão de (7a.ii) procura ajustá-la a assunções correntes sobre a estrutura sintagmática: por exemplo, se V está em Infl em português, então advérbios à esquerda de $\mathrm{V}$ não estão dentro da projeção máxima de $\mathrm{V}$; portanto, na formulação de $\mathrm{N} \& \mathrm{~V}$, não se pode integrar já ao $\phi$ de conhecia em (8b). Para capturar casos como este, utilizamos a noção de "modificador de X", pela qual entendemos todo constituinte semanticamente relacionado a $\mathrm{X}$ - seja argumento, adjunto, especificador ou um elemento funcional. Sobre conseqüências disso, ver a nota 8 aqui.

Com relação a (7b) e (7c), vale observar que são regras de construção de grades métricas: expressam a proeminência acentual (o 'núcleo') de um constituinte prosódico de linha n projetando-o como um asterisco na linha n+1, como em (8). Lembramos que, para Halle \& Vergnaud (1987), o nível da palavra fonológica corresponde à linha 3; o do sintagma fonológico, à linha 4; e o do grupo entoacional, à linha 5. Ver Kenstowicz (1993, cap. 10) para uma apresentação introdutória da teoria de Halle \& Vergnaud.

Ainda sobre (7c), assumimos, como é comum na literatura (cf. N\&V, cap. 7, GHINI, 1993, entre outros), que o grupo entoacional - constituinte imediatamente superior ao sintagma fonológico na hierarquia prosódica - é o constituinte fonológico que corresponde, em regra, mas não necessariamente, à frase.

${ }^{4}$ Analisamos aqui advérbios como satisfatoriamente como sendo compostos de duas palavras fonológicas, embora nada do que sugerimos neste artigo dependa disso. Note-se ainda que o acento secundário mais saliente do $\phi$ satisfatoriamente cai em -tis-, e não em -to-, como efeito de um processo de stress retraction eurrítmico. Para uma discussão recente de processos semelhantes em PB, ver Sandalo \& Truckenbrodt (2002).

${ }^{5} \mathrm{Na}$ verdade, Costa (1998) oferece uma outra análise para a distribuição dos advérbios nas seções finais do capítulo 2; mas não discutiremos essa alternativa, já que envolve assunções não canônicas sobre as estruturas de modificação adverbial. Por exemplo, nesta análise a ordem [V Compl ADJUNTO] com advérbios de modo resulta de movimento do VP para a posição de Spec do advérbio, como em (i) (cf. COSTA, 1998, p.84, (134)): 


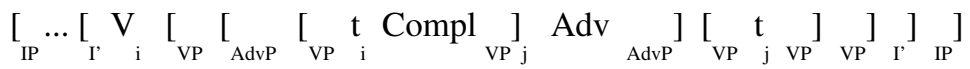

${ }^{6}$ João Costa apresenta outro argumento, baseado em propriedades de extração dos complementos em posição final em inglês. Como não apresenta fatos do português correspondentes, ignoraremos esse argumento aqui, notando que deve ser reavaliado no caso de as observações feitas no presente artigo serem extensíveis ao inglês.

7 É claro que é preciso definir explicitamente o que conta como "ramificado" em (23). Para N\&V, o que parece contar é "ramificação sintática"; mas, a nosso ver, isso faria pouco sentido em se tratando da constituição prosódica da frase. Com efeito, Ghini (1993) argumenta que a reanálise é condicionada por princípios de eurritmia, entre os quais inclui a busca por uniformidade na segmentação prosódica da frase - isto é, ela deve ser segmentada em sintagmas com aproximadamente o mesmo grau de ramificação prosódica. Acreditamos que a posição de Ghini é a correta, mas, por razões de espaço, não nos estenderemos sobre essa questão aqui.

Note-se também que a regra de reanálise em (23) se aplica a modificadores (cf. fn. 3), e não apenas a complementos, como na formulação de N\&V. Essa generalização nos permitirá integrar advérbios pós-verbais ao $\phi$ do verbo, o que será instrumental em nossa explicação para o contraste entre NPs e PPs em (23)-(24).

${ }^{8}$ Parece-nos que a seqüência francês satisfatoriamente pode formar um $\phi$ no caso de ser o foco da frase, como em (Pàulo fála)(francès satìsfatoriaménte)(e inglès terrìvelménte).

Esclarecemos que, embora nossa regra de formação de $\phi$ 's em (7a) permita que o sujeito se integre ao $\phi$ do verbo - como nas segmentações em discussão -, muitos pesquisadores argumentam que isso não é possível; ver Ghini (1993), Truckenbrodt (1999) e Sandalo \& Truckenbrodt (2002). A nosso ver, a possiblidade é demonstrada claramente por exemplos como (Pàulofála)(mùitas línguas)(satìsfatoriaménte)", em contraste mínimo com (9) em função dos princípios de eurritmia mencionados na nota 7. Sandalo \& Truckenbrodt oferecem como argumento a impossibilidade de stress retraction em *(Jòse cóme) e *(Càfe quéima), julgamento com o qual concordamos. Entretanto, para nós, exemplos como (Que práto)(Jòse cóme)(a tòda hóra)? e (Càfe quéima)(quàndo férve)" são bastante aceitáveis, indicando que a restrição observada por Sandalo \& Truckenbrodt não é absoluta em PB e tem, possivelmente, a ver com a pequena extensão de seus exemplos. Talvez, um princípio de eurritmia exija que um grupo entoacional contenha mais de um $\phi$ sempre que possível. 
${ }^{9}$ Talvez a melhor formulação de (24) deva considerar outras unidades prosódicas que não a sílaba. Por exemplo, Filomena Sandalo sugere que (24) parece uma restrição contra sintagmas fonológicos formados por um pé degenerado. Uma outra possibilidade - mais coerente com a hierarquia prosódica de $\mathrm{N} \& \mathrm{~V}$ - é que a unidade pertinente é a imediatamente inferior ao sintagma fonológico, isto é, a palavra fonológica. Adotaremos aqui, entretanto, a sílaba porque nos permite tratar dos advérbios monossilábicos sem maiores complicações.

${ }^{10}$ Filomena Sandalo observa que, se a melhor segmentação prosódica de (21a) fosse (25d), o acento primário de francês deveria sofrer retração (cf. Sandalo \& TRUCKENBRODT, 2002), resultando em (Joáo)(fàla frànces bém), o que parece incorreto. Concordamos com esse julgamento, mas não com o de que a melhor curva acentual para (21a) seja (25c): para nós, a melhor solução parece (25d), em que francês não recebe proeminência acentual e há um lapso entre o acento secundário de fala e o acento frasal de bem. Possivelmente, (21a) ilustra um caso de stress clash resolvido por stress deletion, e não por stress retraction. A ausência de stress retraction com francês não surpreende: Sandalo \& Truckenbrodt (2002) mencionam que alguns de seus informantes também não admitiram stress retraction com o substantivo chinês - obviamente, idêntico a francês no que é pertinente. Para nós, o acento secundário omitido em francês, possivelmente em razão do stress clash, volta a se manifestar em (Joáo)(fàla rùsso bém), em que não há stress clash. (Na entoação relevante, o acento de fala é mais proeminente que o de russo; na notação de Chomsky \& Halle (1968), com proeminência inversamente proporcional a valor numérico, teríamos a curva acentual 234 1; isso praticamente reproduz a curva de (25d), que seria 23 _ 1.) ${ }^{11}$ É justo dizer que o problema não é específico da teoria de Cinque, mas de análises que tomam os constituintes sintáticos como o domínio para a aplicação (cíclica) da regra do acento nuclear, como em Halle \& Vergnaud (1987, p.264 e ss.). Aliás, o problema foi logo reconhecido por Chomsky \& Halle (1968, p. 9-10, 371-2), que anteviram a necessidade de "regras de reajuste" responsáveis pela formação de sintagmas fonológicos. 


\section{REFERÊNCIAS}

BELLETTI, A. Aspects of the Low IP Area. In: RIZZI, L. (Org.) The Structure of IP and CP. Oxford: Oxford University Press, 2004. p. 16-50.

CHOMSKY, N.; HALLE, M. The Sound Pattern of English. Cambridge: MIT Press, 1968.

CINQUE, G. A Null Theory of Phrase and Compound Stress. Linguistic Inquiry, Cambridge, v. 24, p. 239-297, 1993.

COSTA, J. Word Order Variation: A Constraint Based Approach. Haia: Holland Academic Graphics, 1998.

COSTA, J. Review of "Focus and the Syntax-Phonology Interface", by Kriszta Sendröi. Glot International, Cambridge, v. 7, n. 9/10, p. 263-268, 2005.

FERNANDES, F. R. Peso Fonológico e Foco Informacional no Sujeito em PE. In: Actas do XXI Encontro da Associação Portuguesa de Linguística, v. 1, p.67. Porto, Portugal, 2005.

GHINI, M. $\phi$-Formation in Italian: A New Proposal. Toronto Working Papers in Linguistics, Toronto, v. 12, n. 2, p. 41-78, 1993.

HALLE, M.; VERGNAUD, J.-R. An Essay on Stress. Cambridge: MIT Press, 1987.

JOHNSON, K. Object Positions. Natural Language and Linguistic Theory, Dordrecht, v. 9, p. 577-636, 1991.

KENSTOWICZ, M. Phonology in Generative Grammar. Cambridge: Blackwell, 1993.

NEELEMAN, A; REINHART, T. Scrambling and the PF Interface. In: BUTT, M.; GEUDER, W. (Org.) Projection of Arguments: Lexical and Compositional Factors. Stanford: CSLI Publications, 1998. p. 309-353.

NESPOR, M; VOGEL, I. Prosodic Phonology. Dordrecht: Foris, 1986.

POLLOCK, J.-Y. Notes on Clause Structure. Ms., Université de Picardie, Amiens, 1994.

REINHART, T. Focus - The PF Interface. A aparecer em: Interface Strategies: Reference Set Computation. Cambridge: MIT Press. Ms., 2003. 
SAMEK-LODOVICI, V. Prosody Syntax Interaction in the Expression of Focus. Natural Language and Linguistic Theory, Dordrecht, v. 23, p. 687-755, 2005.

SANDALO, F.; TRUCKENBRODT, H. Some Notes on Phonological Phrasing in Brazilian Portuguese. MIT Working Papers in Linguistics, Cambridge, v. 42, p. 285-310, 2002.

SELKIRK, E. Phonology and Syntax: the Relation between Sound and Structure. Cambridge: MIT Press, 1984.

SELKIRK, E. Sentence Prosody: Intonation, Stress and Phrasing. In: GOLDSMITH, J. (Org.) The Handbook of Phonological Theory. Cambridge: Blackwell, 1995. p. 550-569.

TRUCKENBRODT, H. On the Relation between Syntactic Phrases and Phonological Phrases. Linguistic Inquiry, Cambridge, v. 30, p. 219-255, 1999.

TRUCKENBRODT, H. The Syntax-Phonology Interface. A aparecer em: DE LACY, P. (Org.) The Cambridge Handbook of Phonology. Cambridge: Cambridge University Press. Ms., 2005.

ZUBIZARReTA, M. L. Prosody, Focus and Word Order. Cambridge: MIT Press, 1998. 